\title{
Intralesional pingyangmycin injection sclerotherapy for oral ranulas*
}

\author{
Zhifang Chen ${ }^{1 \#}$, Jiawei Zheng ${ }^{2 \#}$, Shanyong Zhang ${ }^{2 \#}$ \\ ${ }^{1}$ Department of Oral and Maxillofacial Surgery, Hefei Stomatological Hospital, Clinical School of Anhui Medical University, Hefei, \\ China \\ ${ }^{2}$ Department of Oral and Maxillofacial Surgery, Ninth People’s Hospital, College of Stomatology, Shanghai Jiao Tong University \\ School of Medicine, Shanghai, China \\ Email: "zf-1973@163.com, "zhjw@omschina.org.cn, "zhangshanyong@126.com
}

Received 12 March 2013; revised 12 April 2013; accepted 15 May 2013

Copyright (C) 2013 Zhifang Chen et al. This is an open access article distributed under the Creative Commons Attribution License, which permits unrestricted use, distribution, and reproduction in any medium, provided the original work is properly cited.

\begin{abstract}
Objective: To investigate the efficiency of pingyangmycin (PYM) intralesional injection for the treatment of ranulas in clinical practice. Methods: PYM concentrations were $2.0 \mathrm{mg} / \mathrm{ml}(8 \mathrm{mg}$ PYM powder + 1 $\mathrm{ml}$ normal saline $+2 \mathrm{ml} 2 \%$ lidocaine $+1 \mathrm{ml}$ dexamethasone). The mixed PYM solution was intralesional injected into ranulas after drawing out isometric cyst fluid in 3 patients. Results: The ranulas of 3 patients showed total disappearance after the sclerotherapy, and no recurrence was found after 6 months to 3 years' follow-up. Compared to surgical therapy, the PYM sclerotherapy was advocated by clinicians for its advantages of less injury, no scar, less suffering, etc. Conclusions: PYM is an effective sclerosing agent for ranulas. Intracystic injection of PYM may be an optimal method for the treatment of ranulas.
\end{abstract}

Keywords: Ranula; Pingyangmycin; Sclerotherapy

\section{INTRODUCTION}

Ranulas are mucoceles that develop as a consequence of mucous extravasation, which typically present in the floor of mouth from the sublingual gland. Plunging ranulas are mucous extravasation pseudocyst herniating through the mylohyoid muscle. The treatments of ranulas mainly include surgical excision of the ranulas and nosurgical sclerotherapy. Surgical management of ranulas is still the first-choice therapy. However, due to the surgical complications, the latter has been advocated by clinicians for its advantages of less injury, no scar, less suffering, etc.

\footnotetext{
*Funding: Hefei City Science and Technology Bureau (No. 2010-070)

\#Corresponding author.
}

Pingyangmycin (PYM), the single component of bleomycin $A_{5}$, is an anticancer agent that is refined from Streptomyces pingyangensis and shows a strong damage function to vascular endothelial cells. PYM has been used as a conventional sclerosing agent for hemangioma, vascular malformations and lymphatic malformations [1]. PYM also can be used to treat cysts as a sclerosing agent [2]. Recently, it has been reported that PYM is also a relatively effective sclerosing agent for ranulas [3]. According to a series of data obtained about the safety and efficacy of direct puncture injection with PYM in treating superficial cysts, we have used this method to treat ranula since the early days of October 2010. In our study, we attempt to describe our experience and to evaluate the efficacy of intralesional injection with PYM for the treatment of ranulas.

\section{MATERIALS AND METHODS}

\subsection{Patients and Evaluation}

3 clinical cases related to 14 - 22 years old female patients (mean 18.3 years old) were included in our study. All patients' chief complaints were the swelling in the floor of mouth, and suffered from 3 - 35 months. No correlative treatment was performed before accepting PYM sclerotherapy (Figure 1). They underwent sclerotherapy with the direct intralesional injection of PYM between $20^{\text {th }}$ October 2010 and $5^{\text {th }}$ March 2013. The protocol was approved and written informed consent was obtained from them before the procedures. All patients were treated on an outpatient basis.

Initial evaluation of the patients was composed of physical examination, recordings of case history, photograph findings. All patients, treated with local submucous intralesional injection of PYM, didn't undergo acute 


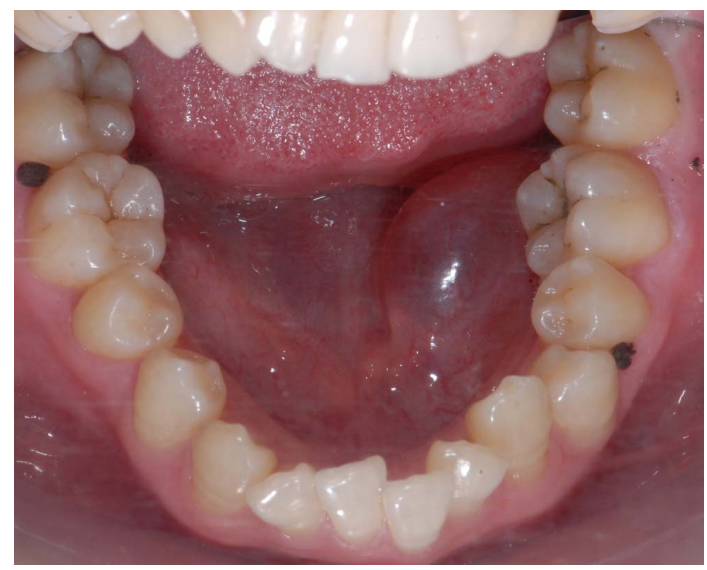

Figure 1. The patient had suffered from a ranula for 35 months, and taken no correlative treatment before accepting treatment.

pain and aggravated swelling any more.

\subsection{Procedure}

For the safety sake, the patient received relevant examinations before accepting sclerotherapy, including blood routine, hepatic and renal function, and chest radiography. No contraindicating was found in the examination results. The PYM solution in these cases was prepared before the procedure. The mixed liquor with $2.0 \mathrm{mg} / \mathrm{ml}$ concentrations was configured as follows: $8 \mathrm{mg}$ of PYM powder (Laibotong Pharmaceutical Co. LTD, Harbin, China) was dissolved in the mixed liquor which was composed of $1 \mathrm{ml}$ normal saline, $2 \mathrm{ml} 2 \%$ lidocaine and $1 \mathrm{ml}$ dexamethasone [2]. The dosage of PYM varied from 0.05 to $0.2 \mathrm{mg} / \mathrm{kg}$ of body weight according previous literatures experience [1].

Half an hour before the procedure, local anesthetic was performed after sterilization of the oral region. A 1.5-inch $(3.8-\mathrm{cm}) 25$-gauge fine-needle was used for the puncture. $1 \mathrm{ml} 2 \%$ lidocaine was directly injected into the critical normal site of the lesion. The normal location for submucous was determined by the needle route.

After the point of the needle found intralesionally, Partial cyst fluid was drawn out before sclerosing agent had been injected (Figure 2, 3). The liquid volume aspirated was about half of the cyst. Otherwise, it is difficulty to puncture again. The sclerosing agent was injected slowly to ensure that PYM was confined solely to the lesions. Finally the injection was stopped when the lesion was filled sufficiently (Figure 4, 5). The volume of sclerosing agent injected was estimated by the initial volume of cyst fluid drew out. Care was taken not to go too far medially and to avoid puncturing out of the cystic wall. The puncture site was gently compressed for 5 - 10 minutes with a bandage. Patients were observed during the procedure the time lasted least 4 hours for the detection

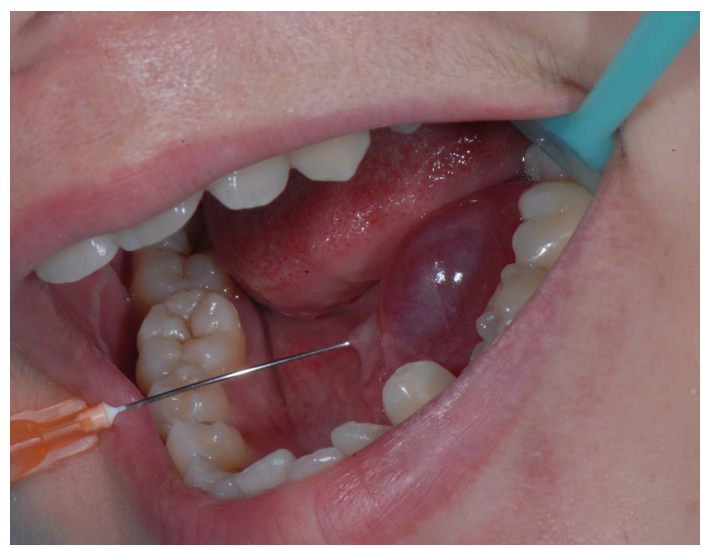

Figure 2. After the point of the needle found intralesionally, Partial cyst fluid was drawn out before sclerosing agent had been injected.

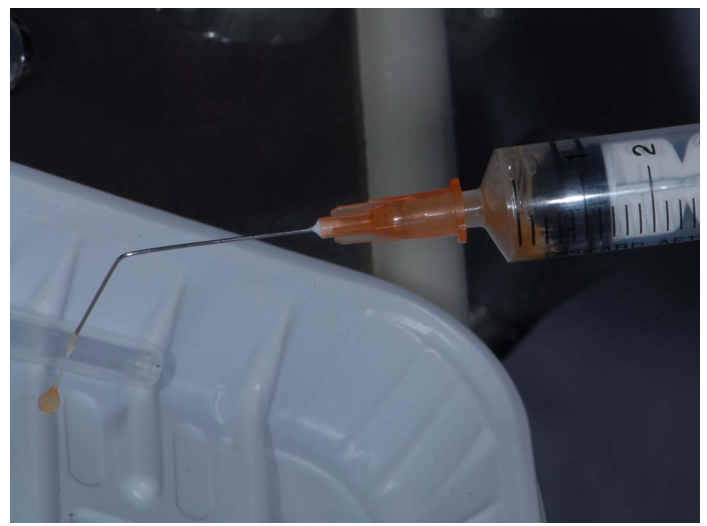

Figure 3. The cyst fluid drawn out show saffron yellow, glutinous liquid after 4 years.

of early complication after the procedure (Figure 6). Systemic corticosteroids (dexamethasone, $10 \mathrm{mg} / \mathrm{d}$ for 3 days) were administered to manage postoperative oral swelling. Nonsteroidal antiinflammatory agents were used for the pain relief when necessary.

\subsection{Definitions and Follow-Up}

The effectiveness of sclerotherapy was assessed on the basis of the follow-up clinical findings and the photograph findings of follow-up (Figure 7). The treatment of the patient, who has not presented oral regional recurrence after the procedure followed-up more than 6 months, is considered to be effective.

\section{RESULTS}

\subsection{Efficacy Outcomes}

Technically, the intralesional PYM injection of sclerotherapy was successful after more than 6 months followed-up. The volume of PYM solution injected was 2.0 - $3.0 \mathrm{ml}$ (mean, dose of PYM $4.9 \mathrm{mg}$ ), PYM was well 


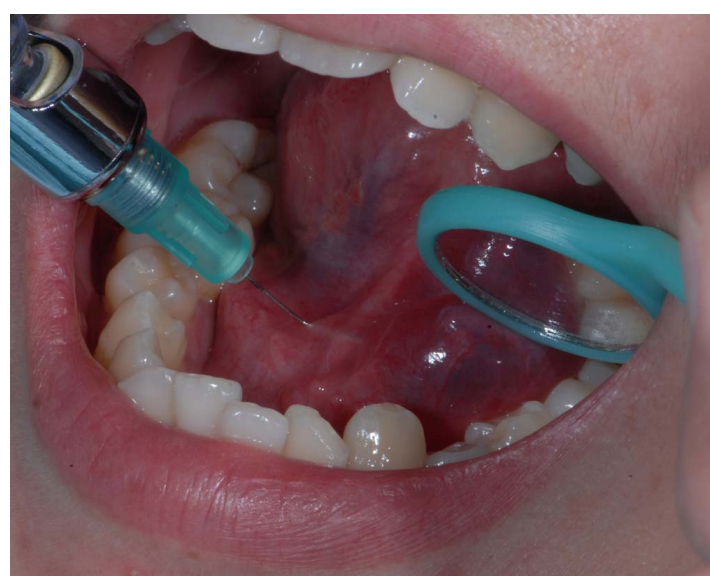

Figure 4. Pingyangmycin was well impregnated in the lesions, The volume of PYM injected was $3.0 \mathrm{ml}$ (total dose of PYM $6.0 \mathrm{mg}$ )

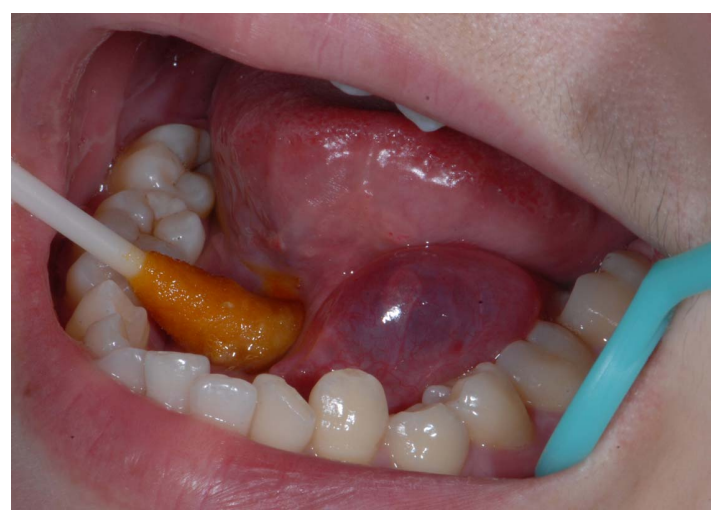

Figure 5. To prevent the cyst liquid mixed residual Pingyangmyein outflow from ruptured cyst, puncture local was pressured for 10 minutes after Pingyangmyein injection

impregnated in the lesions (Figures 4 and 5). Outflow of cyst liquid with residual PYM from ruptured cyst was spitted out. The patient expressed some clinical symptoms such as: local light swelling within 1 week after the procedure, light pain after the cyst rupturing and pain disappearance within 4 - 8 days (mean, 5.3 days). At the same time, the articulation and swallowing function indisposed because of the swelling cyst displaced and interfered the tongue. The procedure was beneficial for the patient with diffuse lesions (Figure 7). The results were reported in the Table 1.

\subsection{Safety Outcomes}

Local swelling and pain in the floor of mouth disappeared after the administration of anti-inflammatory agents and oral care. Others complications, such as acute oral inflammation, infection, hemorrhage, mucous necrosis, oral scar, symptomatic embolism of sclerosing agent into submaxillary gland duct, blood routine, hepatic and renal

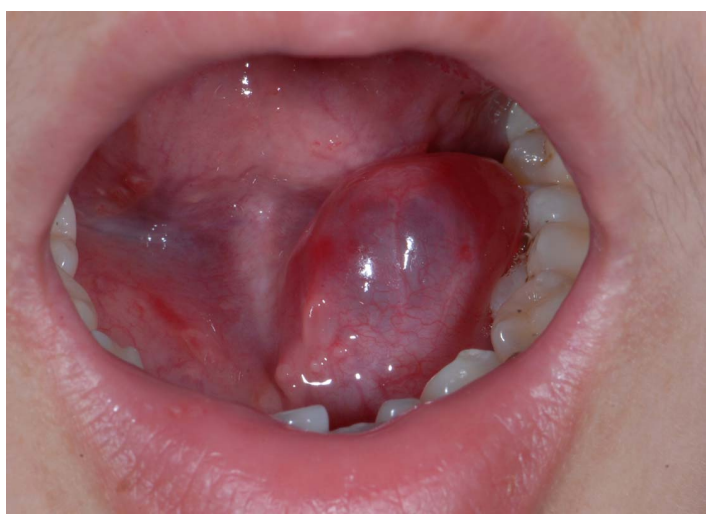

Figure 6. Patients have been observed during the procedure and been for at least 4 hours after the procedure for detection of early complications. Local swelling and pain in the floor of mouth were light. Others complications, such as acute oral inflammation, hemorrhage, and symptomatic embolism of sclerosing agent into submaxillary gland duct were not observed.

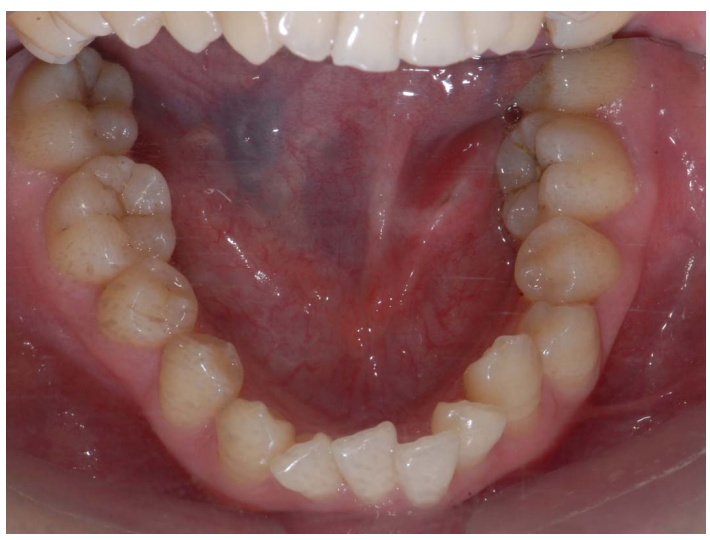

Figure 7. Local bump was disappeared after Pingyangmyein injection 2 weeks.

function, and pulmonary fibrosis, and so on, were not observed during the follow-up periods.

\section{DISCUSSION}

Ranulas is a kind of pseudocyst that has been developing as a result of mucous extravasation from the sublingual gland which can be originated from obstruction of excretory ducts or extravasation and subsequent accumulation of saliva caused by trauma [4]. It is classified into 3 clinical types according to the sites of primary swelling: oral ranula, plunging ranula, and mixed ranula. Oral ranula often presents as fluctuation, soft mass with light blue colour which locates between the mucosa and muscles in the floor of mouth and may displace the tongue and interfere with oral function when the cyst extends.

A variety of therapeutic modalities have been reported to manage ranulas in the past literatures, mainly including surgical resection of the lesion and/or sublingual 
Table 1. The results of PYM sclerotherapy.

\begin{tabular}{ccccccc}
\hline Patient No. & Age (y)/Sex & Location & Aspiration (cc) & Injection (cc) & Duration of Follow-up (mo) & Result \\
\hline 1 & $22 / \mathrm{F}$ & Left sublingual & 3.0 & 3.0 & 35 & total disappearance \\
2 & $19 / \mathrm{F}$ & Right sublingual & 2.4 & 2.4 & 13 & total disappearance \\
3 & $14 / \mathrm{F}$ & Left sublingual & 2.0 & 2.0 & 6 & total disappearance \\
\hline
\end{tabular}

gland, marsupialization and sclerotherapy using sodium morrhuate [5-7], OK-432 [8,9], ethanol [10], trichloroacetic acid [11], etc. Surgical resection of the lesion and/or sublingual gland is the mainstay treatment of ranulas. However, the effect is still controversial, due to the various kinds of complications such as recurrence, tongue hypesthesia, bleeding/hematoma, postoperative infection, Wharton's duct injury, etc. In addition, surgical therapy might be difficult for infant and child patients with ranulas under local anesthesia. Marsupialization is not approved of adoption because of its high recurrence rate. To avoid the complications associated with the surgical procedures, nonsurgical sclerotherapy, reported to have the advantages of minimal scaring, little morbidity, and few complications, has been better to treat oral and plunging ranulas, compared with surgical procedures.

According to the literatures, there are several kinds of sclerosing agents that are used clinically. For example, OK-432, a lyophilized mixture of low-virulence group A Streptococcus pyogens with penicillin $G$ potassium, has been applied to the treatment of patients with lymphatic malformations due to its cytotoxic action against endothelial cells and the fibrotic changes related to cytokine action in the lymphatic malformations [12]. Ogita et al. first reported intracystic injection of OK-432 for cystic hygroma in 1987 [12]. Henceforth, the effectivences and safety of intralesional injection of OK-432 for lymphangioma has been reported repeatedly $[13,14]$. Recently, it was reported that OK-432 could also be used in ranulas by increasing absorption and decreasing saliva production, resulting in the collapse and adhesion of the pseudocyst [11-15]. However, patients often suffered from a lot of troubles because of its high incidence of recurrence and repeated intralesional injection. Rhoa et al. reported OK-432 sclerotherapy of plunging ranula in 21 patients, only 7 patients (33.3\%) showed total shrinke and resolution, and the overall recurrence rate after each injection was 47\% (16 of 34 injections in 21 patients) [8].

Pingyangmycin (PYM) has been successfully used in intralesional injection treatment of cystic hydromas and haemangiomas, based specifically on a high sclerosing effect on vascular endothelium [2]. It is a kind of bleomycin $\mathrm{A}_{5}$ isolated from many components of bleomycin made in China which can affect $G_{2}$ and $S$ phases of fast dividing cells and causes breakage of single-stranded DNA via preventing DNA repair by inhibiting DNA ligase. Intralesional injection of PYM brings the drug into direct contact with the endothelial lining and destroys the endothelial cells, resulting in sclerostenosis of the lumen, and has been proved to be an effective, inexpensive, and safe method for venous malformations of oral and maxillofacial region [16,17]. Yang et al. [3] hypothesize that PYM may cause damage of the cystic wall of the ranulas, resulting in local fibrosis which subsequently eliminate the cyst of ranulas and yield excellent treatment effects.

The cystic wall of oral ranula is similar to the endothelial lining in that it is also very thin. The effectiveness of PYM for treating the cystic hydromas and haemangiomas might also be effective for treating ranulas. Zhao et al. [18] attempted PYM scleroyherapy in 785 cases of sublingual cyst, 756 patients were cured completely, others had significant improvement, and concluded that it is a safe and effective therapy for sublingual cyst, and can be used as a treatment of choice in some selected cases. The similarity conclusion was obtained by other Chinese resarchers. PYM expressed more significant effective compared with OK-432. Similarly, in our study, the cyst showed total disappearance after PYM sclerotherapy about 2 weeks (Figure 7) in 3 patients with ranulas. The reason for the different cure time in our study may be related to a different concentration of PYM in cyst, as the different volume injected of PYM solution and the different residual cystic fluid.

Zhou et al. [19] believe, to achieve the desired effect, that concentration is more important than dose per treatment. However, most authors didn't report the concentration they used and the dose varied greatly $[17,18]$. The most serious potential complication of using PYM is pulmonary fibrosis in cancer therapy. The risk of this toxicity is felt minimal when, as suggested by Sung et al. [20] that the dose per treatment be kept under $1 \mathrm{mg} / \mathrm{kg}$ per session and no more frequently than an interval of a week, with the total dose limited to $5 \mathrm{mg} / \mathrm{kg}$. We believe that the use of minimum per $\mathrm{kg}$ dose as described in the literature is not mandatory for the sclerosing effect of PYM to occur, and that the maximum dose and concentration are important for efficiency and safety.

Higher PYM concentrations $2.0 \mathrm{mg} / \mathrm{ml}$ (8 mg PYM powder $+1 \mathrm{ml}$ normal saline $+2 \mathrm{ml} 2 \%$ lidocaine $+1 \mathrm{ml}$ dexamethasone) was adopted in our study. Although most of ranulas described as "mucous extravasation cysts [21]" without epithelial lining, should have a higher rate of response to intralesional PYM injection in theory, Partial residuary and secretory cyst fluid should dilute the 
concentrations of PYM. We achieved the desired clinic effect in fact. The addition and peroral of dexamethasone is to prevent fever, pain and swelling post injection. We believe that this modality is more rational and further clinical trials are required for validation.

The advantage of PYM intralesional injection for oral ranulas less trauma, low recurrence rate, and it is simple and practicable. While surgery of ranula is not just only selectable treatment which is a more complicated procedure with the sequela of leaving some residual lesion and the chance of recurrence. Other complications of surgery include temporary or permanent paraesthesia in the distribution of the lingual nerve, transient or permanent marginal mandibular nerve palsy, wound infection, and stitch granuloma. What's more, PYM is a potential better sclerosing agent than others reported, such as OK-432, Iodine tinctune, Trichloroacetic acid (TDA), sodium morrhuate, etc. The mechanism of PYM sclerotherapy is that PYM can affect cell division directly via preventing DNA, which leads to apoptosis. We speculated that the cystic wall cell might be necrotic and ruptured after the injection of PYM solution. All 3 patients were cured after only one injection and showed no recurrence followed-up for 6 - 35 months. Finally, the advantage of PYM sclerotherapy is that the complications are minimal, as seen in the Zhao's paper [18]. In our study, minor discomforts, such as light swelling at the injection site, light pain in rupture site, were seen within the first week after the injection and diappeared after 2 weeks. There were no more complications found in our study probably because the number of the collected patients was insufficient.

\section{CONCLUSION}

Our results suggest that PYM scleroyherapy of ranulas is a safe and significantly effective therapy, which may be used as a primary or first-choice treatment of ranulas. Further studies may be desired to focus on the ranula animal models to investigate the effects and side effects of this method as well as its exact mechanisms. Our prospect is to find a safe and convenient concentration that is less suffering to patients with ranulas in the future.

\section{REFERENCES}

[1] Zhang, J., Chen, C. and Zhang, Z. (2003) Intralesional injection of pingyangmycin for hemangiomas and vascular malformations in oral and maxillofacial region: A systematic review of the Chinese literature. China Journal of Oral and Maxillofacial Surgery, 1, 102-105.

[2] Muir, T., Kirsten, M., Fourie, P., et al. (2004) Intralesional bleomycin injection (IBI) treatment for haemangiomas and congenital vascular malformations. Pediatric
Surgery International, 19, 766-773. http://dx.doi.org/10.1007/s00383-003-1058-6

[3] Yang, X.J., Zheng, J.W., Zhou, Q., et al. (2010) Intracystic injection of pingyangmycin (PYM) might be a more favorable option for treatment of oral and plunging ranulas. Shanghai Kou Qiang Yi Xue, 19, 447-448.

[4] de Visscher, J.G., van der Wal, K.G. and de Vogel, P.L. (1989) The plunging ranula. Pathogenesis, diagnosis and management. Journal of Cranio-Maxillofacial Surgery, 17, 182-185. http://dx.doi.org/10.1016/S1010-5182(89)80020-4

[5] Gilbert, L.D., Bakos, L.H. and Graves, R.W. (1981) Sodium morrhuate-An alternative in the treatment of soft tissue hemangiomas. Review of the literature and case reports. West Virginia Dental Journal, 55, 11-15.

[6] Zhao, J.H., Zhang, W.F. and Zhao, Y.F. (2004) Sclerotherapy of oral and facial venous malformations with use of pingyangmycin and/or sodium morrhuate. International Journal of Oral and Maxillofacial Surgery, 33, 463-466. http://dx.doi.org/10.1016/j.ijom.2003.10.003

[7] He, W., Gu, A.L. and Shang, J.L. (2007) Comparison of the clinical therapeutic effects between local injection of pingyangmycin and sodium morrhuate on oral and maxillofacial venous malformation. Zhonghua Kou Qiang Yi Xue Za Zhi, 42, 308-309.

[8] Rho, M.H., Kim, D.W., Kwon, J.S., et al. (2006) OK-432 sclerotherapy of plunging ranula in 21 patients: It can be a substitute for surgery. American Journal of Neuroradiology, 27, 1090-1095.

[9] Patel, M.R., Deal, A.M. and Shockley, WW. (2009) Oral and plunging ranulas: What is the most effective treatment? Laryngoscope, 119, 1501-1509. http://dx.doi.org/10.1002/lary.20291

[10] Blonski, W.C., Campbell, M.S., Faust, T., et al. (2006) Successful aspiration and ethanol sclerosis of a large, symptomatic, simple liver cyst: Case presentation and review of the literature. World Journal of Gastroenterology, 12, 2949-2954.

[11] Kim, K.H., Sung, M.W., Roh, J.L., et al. (2004) Sclerotherapy for congenital lesions in the head and neck. Otolaryngology_Head and Neck Surgery, 131, 307-316. http://dx.doi.org/10.1016/j.otohns.2004.02.018

[12] Ogita, S., Tsuto, T., Nakamura, K., et al. (1994) OK-432 therapy in 64 patients with lymphangioma. Journal of Pediatric Surgery, 29, 784-785. http://dx.doi.org/10.1016/0022-3468(94)90370-0

[13] Brewis, C., Pracy, J.P. and Albert, D.M. (2000) Treatment of lymphangiomas of the head and neck in children by intralesional injection of OK-432 (picibanil). Clinical Otolaryngology, 25, 130-134. http://dx.doi.org/10.1046/j.1365-2273.2000.00338.x

[14] Sung, M.W., Lee, D.W., Kim, D.Y., et al. (2001) Sclerotherpy with picibanil (OK-432) for congenital lymphatic malformation in the head and neck. Laryngoscope, 111, 1430-1433.

http://dx.doi.org/10.1097/00005537-200108000-00020

[15] Bloom, D.C., Perkins, J.A. and Manning, S.C. (2004) Management of lymphatic malformations. Current Opin- 
ion in Otolaryngology \& Head and Neck Surgery, 12, 500-504.

http://dx.doi.org/10.1097/01.moo.0000143971.19992.2d

[16] Kim, M.G., Kim, S.G., Lee, J.H., et al. (2008) The therapeutic effect of OK-432 (picibanil) sclerotherapy for benign neck cysts. Laryngoscope, 118, 2177-2181. http://dx.doi.org/10.1097/MLG.0b013e3181864acf

[17] Zhi, K., Wen, Y., Li, L., et al. (2008) The role of intralesional Pingyangmycin in the treatment of venous malformation of facial and maxillary region. International Journal of Pediatric Otorhinolaryngology, 72, 593-597. http://dx.doi.org/10.1016/j.ijporl.2008.01.007

[18] Zhao, S.F., Shou, W.D., Hu, Q.G., et al. (2010) Treatment of sublingual cyst with intracystic injection of Pinyangmycin: Clinical results in 785 consecutive cases. China Journal of Oral and Maxillofacial Surgery, 8, 4749.
[19] Zhou, Q., Zheng, J.W., Yang, X.J., et al. (2010) Concentration is more important than dose when using intralesional Pingyangmycin injection for treatment of vascular malformations. Shanghai Kou Qiang Yi Xue, 19, 220221.

[20] Sung, M.W., Chang, S.O., Choi, J.H., et al. (1995) Bleomycin sclerotherapy in patients with congenital lymphatic malformation in the head and neck. American Journal of Otolaryngology, 16, 236-241.

http://dx.doi.org/10.1016/0196-0709(95)90149-3

[21] Praetorius, F. and Hammarstrom, L. (1992) A new concept of the pathogenesis of oral mucous cysts based on a study of 200 cases. The Journal of the Dental Association of South Africa, 47, 226-231. 